\title{
Styrene-diene Block-copolymers Reinforced with Bentonite
}

\author{
PAUL GHIOCA, LORENA IANCU*, RAMONA MARINA GRIGORESCU, BOGDAN SPURCACIU, CRISTIAN ANDI NICOLAE, \\ AUGUSTA RALUCA GABOR \\ The National Institute for Research \& Development in Chemistry and Petrochemistry - ICECHIM, 202 Splaiul Independentei, \\ 060021, Bucharest, Romania \\ This paper presents the reinforcement effect of bentonite (0 - 30\%) on styrene-diene block-copolymers in \\ correlation with the biphasic morphology of these thermoplastic elastomers.
}

Keywords: SBS, SIS, bentonite, reinforced composites.

The styrene-diene block-copolymers with a majority diene composition presents vulcanized elastomer properties at ambient temperature due to the segregation of polystyrene blocks as dispersed domains into the diene phase, thus ensuring the physical crosslinking of the polydiene. The phenomenon occurs due to the thermodynamic incompatibility between the polystyrene and diene blocks. At temperatures above the polystyrene phase $\mathrm{Tg}$, the block-copolymers have a plastic behavior and can be thus processed on thermoplastics specific equipment. At cooling the phases segregation occurs and the material behaves as a vulcanized elastomer $[1,2]$.

The enhanced physical-mechanical properties and the possibility of processing as a thermoplastic material with reduced labor costs led to a steady increase of blockcopolymers production and an annual growth of $3-4 \%$ until 2018 is foreseen [3].

The thermoplastic behavior of styrene-diene blockcopolymers allows the facile obtaining of their composites with various fillers even during the direct processing on injection, extrusion and calendering equipment [4].

The reinforcement with mineral fillers of styrene-diene block-copolymers lead to mechanical properties balancing improves the thermal behavior at higher temperatures and increases the resistance to chemical agents, wear and thermal degradation $[1,5-8]$.

The reinforcement with mineral fillers reduces the cost price of the composite material and allows the increasing of the using proportion of styrene-diene block-copolymers, especially in the production of membranes and waterproof adhesive foils [9 -11], shoes soles [12], protection gloves [13] and bitumen [14] and polyolefin modification additive.

This paper presents the reinforcement effect of bentonite on styrene-butadiene and styrene-isoprene blockcopolymers with $30 \%$ polystyrene content.

\section{Experimental part}

The reinforcement study with bentonite was performed using a star styrene-butadiene (SBS) and a linear styreneisoprene (SIS) block-copolymer synthetized by sequential anionic polymerization of monomers in cyclohexane solution, the reaction being initiated with n-butyl lithium [15 - 18]. After the synthesis, the block-copolymers were stabilized with 1\% 2,6-di-tert-butyl-4-methylphenol (TOPANOL OC) directly in the polymerization cyclohexane solution.

The block-copolymers separation from the solution was performed by stripping with hot water and water vapor; finally the polymers were dried in an oven at $60^{\circ} \mathrm{C}$ under reduced pressure.

The molecular masses of the polymers and the component blocks collected during different synthesis phases were determined by gel permeation chromatography (GPC). The physical-mechanical properties were determined on films with a thickness of about $1 \mathrm{~mm}$ obtained by centrifugal casting at maximum $60^{\circ} \mathrm{C}$ from the toluene solution, according with standardized requirements for styrene-diene block-copolymers characterization.

The properties of styrene-diene block-copolymers are presented in table 1.

\begin{tabular}{|c|l|c|c|}
\hline $\begin{array}{c}\text { Crt. } \\
\text { no. }\end{array}$ & \multicolumn{1}{|c|}{ Property } & SBS & SIS \\
\hline 1. & Polystyrene content,\% & 31.5 & 30.8 \\
\hline 2. & Total molecular mass, g/mole & 182,300 & 121,800 \\
\hline 3. & Polystyrene block molecular mass, g/mole & 14,400 & 18,600 \\
\hline 4. & Polybutadiene block molecular mass, g/mole & 124,700 & - \\
\hline 5. & Polyisoprene block molecular mass, g/mole & - & 84,600 \\
\hline 6. & Yield, MPa & 5.18 & - \\
\hline 7. & Elongation modulus at 300\%, MPa & 4,66 & 3.52 \\
\hline 8. & Tensile strength, MPa & 22.8 & 14.1 \\
\hline 9. & Elongation at break, \% & 780 & 1360 \\
\hline 10. & Remanent elongation, \% & 10 & 14.6 \\
\hline 11. & Hardness, ${ }^{\circ}$ Sh A & 67 & 52 \\
\hline
\end{tabular}

Table 1

PHYSICO-MECHANICAL PROPERTIES OF STYRENE-DIENE BLOCK-COPOLYMERS

\footnotetext{
*email; lorena.iancu@icechim.ro
} 
The block-copolymers reinforcement was achieved using bentonite Chioar Valley with more than $60 \%$ montmorillonite with interlayer spacing of $15.1 \AA$.

After grinding, the bentonite presented the following composition of particle size: residue on sieve - $R_{1}=0 \%$; $\mathrm{R}_{0.5}=0.2 \% ; \mathrm{R}_{0.063}=65.8 \% ; \mathrm{R}_{0.04}=97.1 \% ; \mathrm{R}_{0.025}=100 \%$.

The composites were obtained by bentonite dosing in $5 \%$ steps in the range of $0-30 \%$ into the $20 \%$ blockcopolymers toluene solution, under intensive stirring.

The desolvation was carried out by centrifugal casting, a method that ensures a uniform distribution of bentonite during rotation due to the centrifugal forces [19]. The blockcopolymers solution containing the dispersed bentonite was added in small proportions in a long time to minimize the formation of a reinforcing gradient in the film thickness.

Toluene was used in composites obtaining - being recommended also by other authors [20-22] because it is a non-selective solvent for polystyrene, polybutadiene, respectively polyisoprene blocks [22] thus avoiding the morphological changes in the biphasic structure of styrenediene block-copolymers that could disrupt the interpretation of the reinforcing effect.

The composites tensile properties were determined on stamped specimens from the obtained films with a 0.8-1 $\mathrm{mm}$ thickness, using a FPZ 100 dynamometer, with an elongation rate of $500 \mathrm{~mm} / \mathrm{min}$, according to SR EN ISO 527-96.

Temperature modulated differential scanning calorimetry (TMDSC) determinations were carried out with a DSC Q2000 (TA Instruments) assisted by a Liquid Nitrogen Cooling System (LNCS), in the temperature range -150 $+150^{\circ} \mathrm{C}$, using $\mathrm{T}_{\text {zre }}$ aluminum pans and helium as purge gas at a flow rate of $30 \mathrm{~mL} / \mathrm{min}$. Method: Heat-Cool-Heat, MTDSC Heat only; Cycle 1: Ramp $40^{\circ} \mathrm{C} / \mathrm{min}$ to $150^{\circ} \mathrm{C}$; Cycle 2: Modulate $\pm 2.12^{\circ} \mathrm{C}$ every $20 \mathrm{~s}$; Ramp $40^{\circ} \mathrm{C} / \mathrm{min}$ to $-150^{\circ} \mathrm{C}$; Cycle 3: Modulate $\pm 1.06^{\circ} \mathrm{C}$ every $20 \mathrm{~s}$; Ramp $20^{\circ} \mathrm{C} / \mathrm{min}$ to $150^{\circ} \mathrm{C}$.

Dynamic mechanical properties of elastomer composites were determined on a DMA Q 800 Dynamic Mechanical Analyzer - TA Instruments using the Universal Analysis 2000 software for processing the results. The obtained films with dimensions $10 \times 10 \mathrm{~mm}$ (length $\times$ width) were cut by two using perforating punches according to the apparatus instructions and to the working method. The determinations were carried out from room temperature to $165^{\circ} \mathrm{C}$, with a heating rate of $3^{\circ} \mathrm{C} / \mathrm{min}$, amplitude of $15 \mu \mathrm{m}$, frequency of $1 \mathrm{~Hz}$, using the shear sandwich clamp.

\section{Results and discussions}

The morphological studies from literature certifies that bentonite is embedded only in the elastomeric phase of the styrene-diene block-copolymers and it is relatively uniform distributed in composites due to the high interfacial adhesion between the filler and the polydienes [21, 23, 24].

The polystyrene phase is less affected by bentonite presence, the dimensions and morphology of polystyrene domains are not significantly influenced and therefore the crosslinking degree is not affected [25-28].

Embedding the bentonite into the diene phase will lead to an increase in its transition temperature (fig. 1), a phenomenon characteristic to elastomers reinforcement $[27,28]$. A less accentuated increase of diene phase $\mathrm{Tg}$ with increasing bentonite dosage certifies that the elastomer chains mobility is to a small extend affected by the filler presence at this temperature.

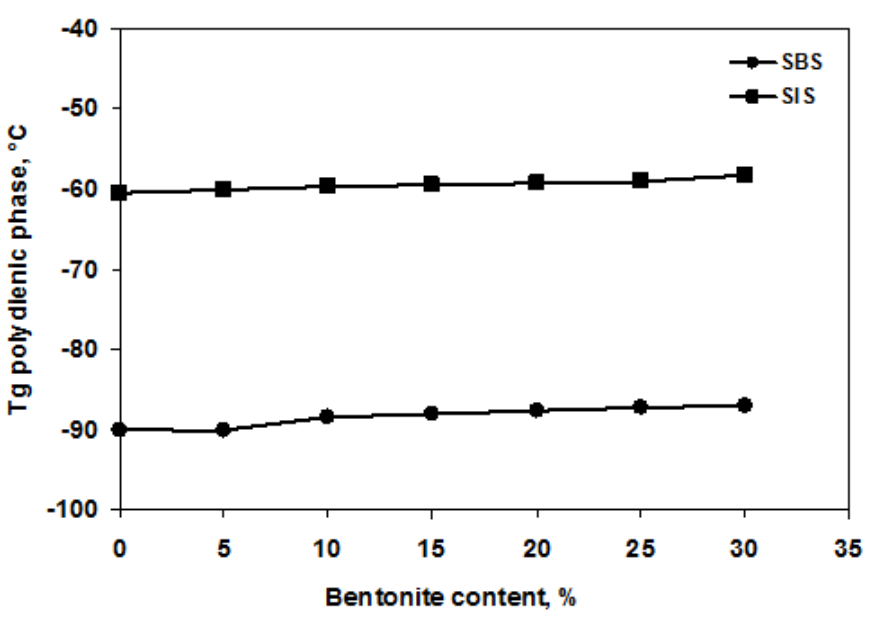

Fig. 1 The polydienic phase $\operatorname{Tg}$ (DSC) variation of elastomeric composites with the bentonite content

Bentonite presence in the elastomeric phase prevents the complete segregation of the polydiene in the polystyrene domains which leads to a slightly decrease of the polystyrene phase glass transition temperature, as can be seen in figure 2 .

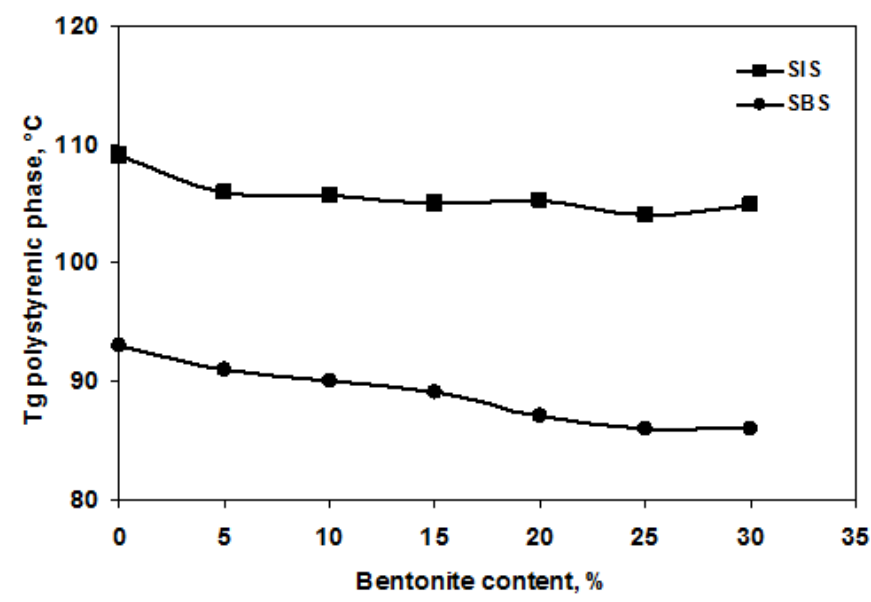

Fig. 2 The polystyrene phase $\operatorname{Tg}$ (DSC) variation of elastomeric composites with the bentonite content

The higher incompatibility of polystyrene with polyisoprene compared to polybutadiene, in correlation with the interphase contact much stronger between bentonite and polyisoprene, leads to a better separation of polystyrene domains from the composite, the effect being emphasized by the higher values of styrene-isoprene blockcopolymers glass transition (fig. 2).

Because the polystyrene phase is not significantly influenced by bentonite presence, the domains morphology does not undergo important changes and the reinforcement effect of the filler occurs especially in the elastomer phase of the styrene-diene block-copolymers $[25,26,29,30]$.

Reinforcing the styrene-diene block-copolymers with bentonite has as a first effect the changing of the elastic behavior of composites and it is highlighted by the storage modulus variation with the filler dosage (figs. 3 and 4). As it can be seen, the storage modulus for unfilled SBS, respectively SIS block-copolymers is $34.21 \mathrm{MPa}$, respectively $6.75 \mathrm{MPa}$ while for the ones reinforced with $5 \%$ bentonite the storage modulus increases 10 times reaching 423.5 , respectively $79.56 \mathrm{MPa}$. The increase of the storage modulus is not constant as the bentonite dosage increases reaching a plateau at $30 \%$ concentration in case of SIS composites. 


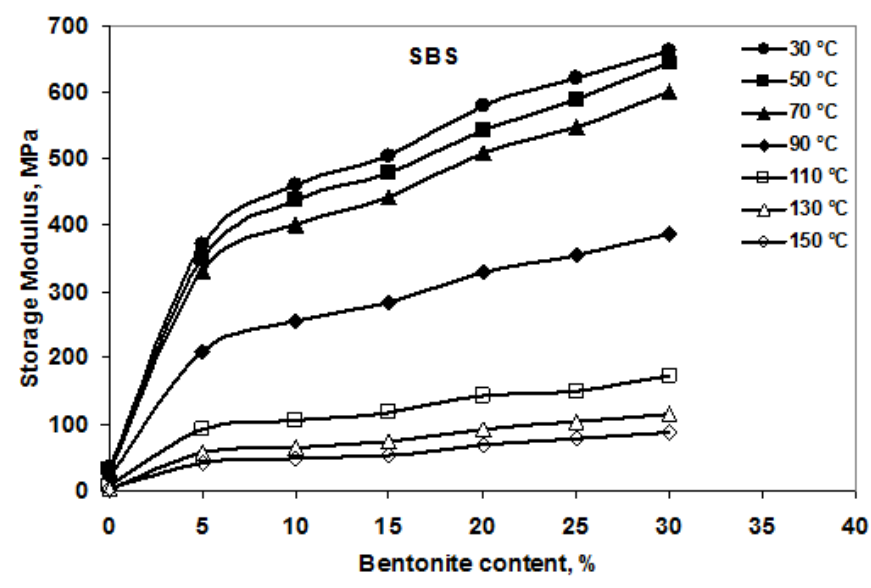

Fig. 3 The storage modulus variation of SBS composites with the bentonite content, at different temperatures

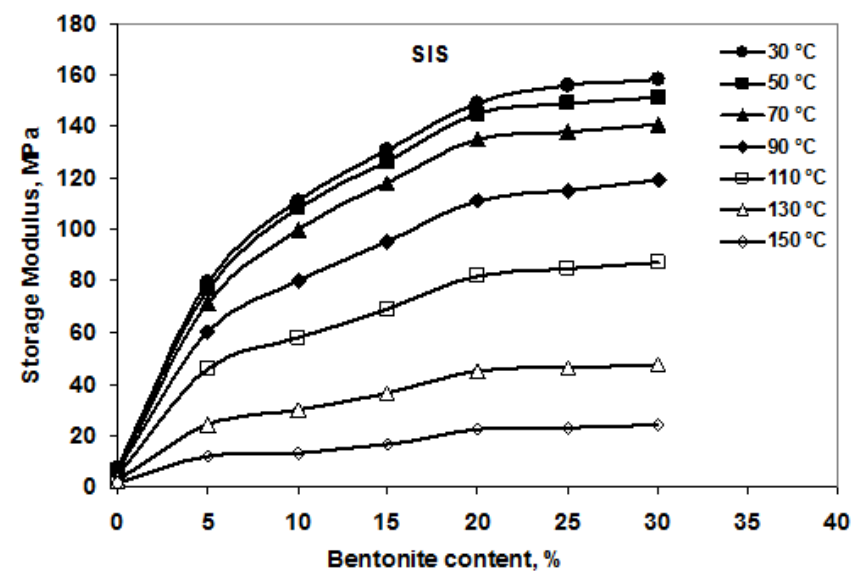

Fig. 4 The storage modulus variation of SIS composites with the bentonite content, at different temperatures

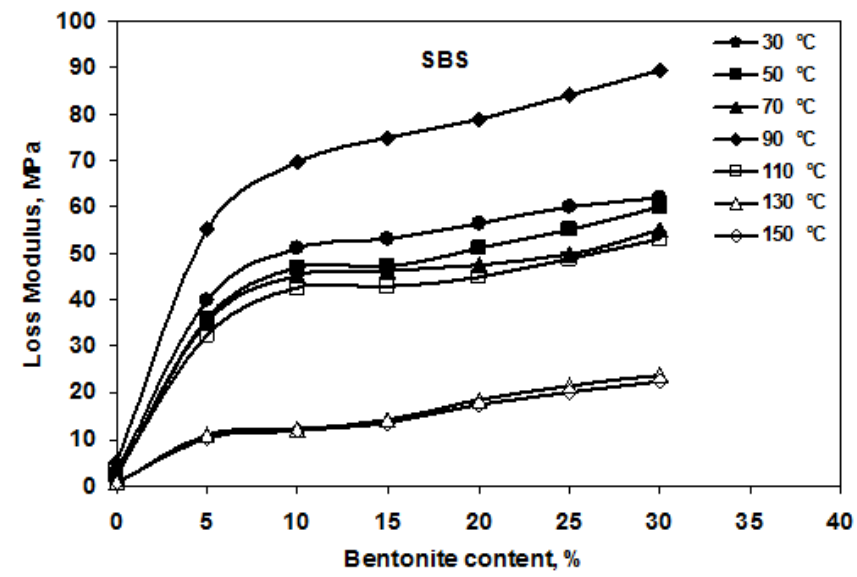

Fig. 5 The loss modulus variation of SBS composites with the bentonite content, at different temperatures

The continuous growth of the composites storage modulus as a result of increasing the bentonite concentration is due to the decrease of elastomer chains mobility produced by the filler [31-36].

The larger storage modulus values of styrene-butadiene block-copolymers composites are due both to the higher masses of polybutadiene block and to the superior entanglement degree of this phase compared to the polyisoprene one [37-39].

The composites behavior depending on the temperature is due to the increase of elastomer macromolecules mobility that can be observed also from the shape of Storage modulus vs Temperature curves that show a slow

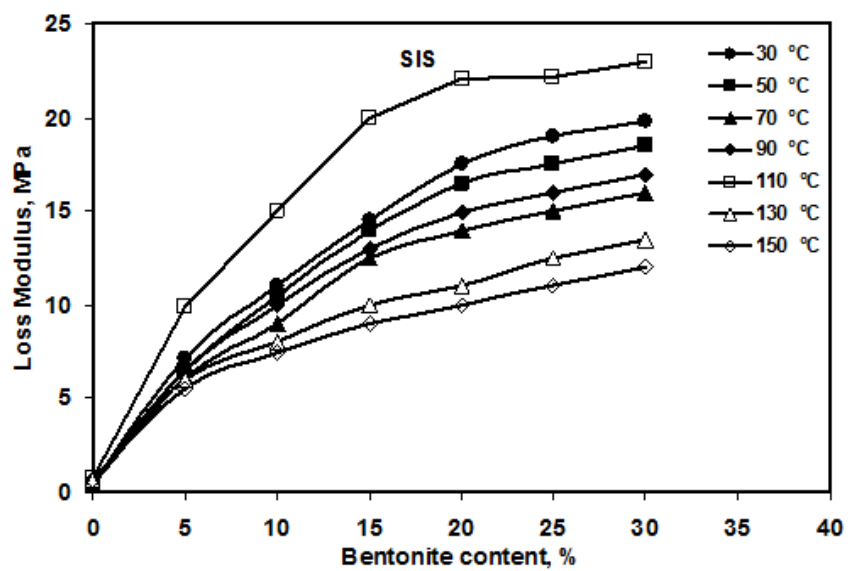

Fig. 6 The loss modulus variation of SIS composites with the bentonite content, at different temperatures

decrease until reaching polystyrene glass transition temperature followed by a sudden decrease in Tg zone after which it appears a new plateau because the physical crosslinking disappears.

It can be observed that, by increasing the bentonite concentration, the loss modulus increases (figs. 5 and 6 ), its higher values in case of styrene-butadiene blockcopolymer are due to the higher molecular mass and to the superior entanglement of polybutadiene chains similarly, as for the storage modulus.

The composites viscosity (loss modulus) decreases as the temperature increases until reaching polystyrene phase $\operatorname{Tg}\left(90^{\circ} \mathrm{C}\right.$ for SBS, respectively $110^{\circ} \mathrm{C}$ for SIS) when the composite softens and the viscosity presents a significant increase. At temperatures higher than polystyrene Tg the viscosity decreases sharply due to the pronounced fluidity of polystyrene blocks.

The loss modulus increase in direct correlation with increasing the bentonite dosage is the consequence of increasing the composites viscosity, phenomenon characteristic to elastomers reinforcement $[8,21]$.

Reinforcing styrene-diene block-copolymers with bentonite will lead to a decrease of the tensile strength and elongation at break, as can be seen in figures 7 and 8 .

Representing the two properties in relative values allows an easier comparative evaluation of the reinforcing effect produced on the two types of block-copolymers.

The more pronounced decrease of the tensile strength of styrene-isoprene block-copolymers composites is mainly due to the lower molecular mass of polyisoprene chains (table 1) compared to polybutadiene ones and thus the reinforcing effect is manifested more intensely.

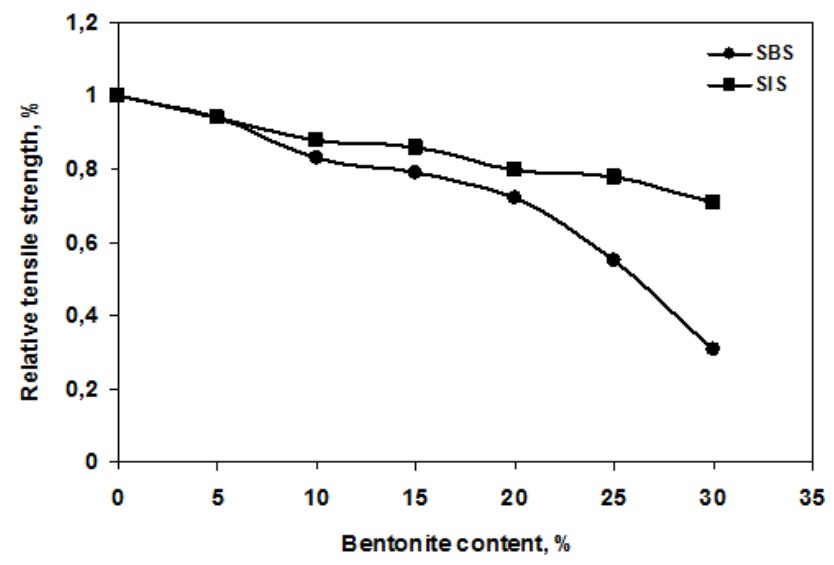

Fig. 7 The tensile strength variation of the elastomeric composites with the bentonite content 


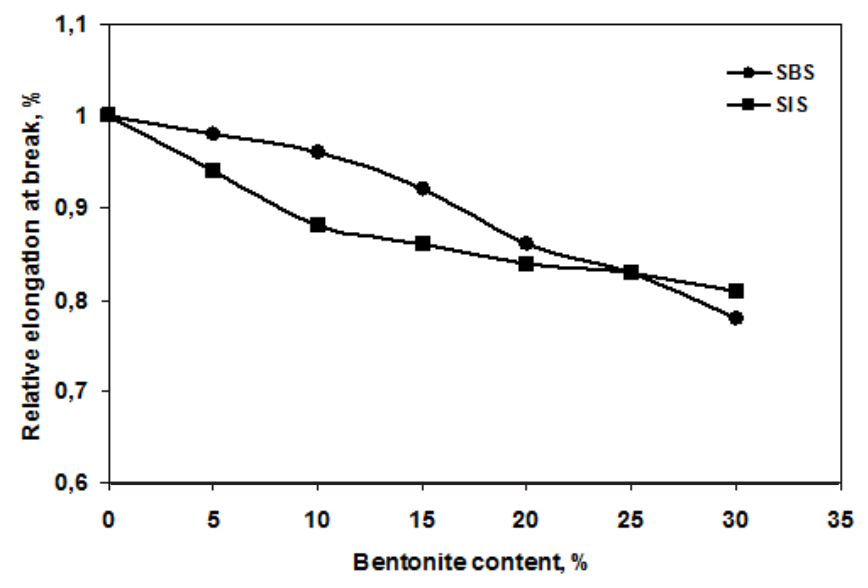

Fig. 8. The elongation at break variation of the elastomeric composites with the bentonite content

According to the performed study, it can be estimated that the bentonite from Valea Chioarului can be successfully used as reinforcing agent for the styrene-diene blockcopolymers.

\section{Conclusions}

The study highlighted the reinforcing effect of bentonite on SBS and SIS block-copolymers.

It was ascertained the bentonite distribution only in the diene phase of block-copolymers, the reinforcing mechanism being influenced both by the biphasic morphology of block-copolymers and by the different adhesion degree of the filler at polybutadiene and polyisoprene.

Acknowledgment: This work was financed by The Romanian National Authority for Scientific Research, UEFISCDI, projectno. PN.16.31.03.01.

\section{References}

1.HOLDAN G., Thermoplastic Elastomers in Applied Plastics Engineering Handbook: Processing and Materials, Elsevier, Oxford, UK, 2011, p. 77.

2.UTRACKI L.A., WILKIE C.A., Polymers Blends Handbook, Springer, 2014.

3.IHS MARKIT, Styrenic Block Copolymers Chemical Economics Handbook (CEH), 2014, p. 1.

4.ASO 0., EGUIZABAL J.I., NAZABAL J., Compos. Sci. Tehnol., 63 (3), 2007, p. 2854.

5.PAUL D.R., ROBESON L.M., Polymer, 49, 2008, p. 3184.

6.PEDRONI L.G., SOTO-OVIEDO M.A., ROSOLEN J.M., FELISBERTI

M., NOGUEIRA A.F., J. Appl. Polym. Sci., 112 (6), 2009, p. 3241.

7.WHELAN A., Polymer Technology Dictionary, Springer, 2012.

8.PAVLIDOU S., PAPASPYRIDES C.D., Prog. Polym. Sci., 33, 2008, p. 1119.

9.*** Patent US no. 5496615A, 1996.

10.*** Patent EP no. 0501838 A2, 1992.

11.*** Patent CN no. 1837316 A, 2006.
12.*** Patent WO no. 2001025331 A1, 2001.

13.*** Patent EP no. 0854174 Al, 1998.

14.VARGAS-HERNANDEZM.A., VAZQUEZ-TORRES H., Revista Mexicana de Ingenieria Quimica, 14 (2), 2015, p. 503.

15.*** Patent RO no. 109850, 1995.

16.HOLDEN G., LEGGE N.G., QUIRK, R.P., SCHRODERE H.E., Thermoplastic Elastomers, Hanser Publisher, Vienna, 2006.

17.HSIEH H.L., QUIRK R.P., Anionic Polymerization, Marcel Dekker, NY, 2008.

18.HADYICHRISTIDIS N., HIRAO A., Anionic Polymerization. Principles, Practice, Strength, Consequences and Applications, Springer, Japan, 2015.

19.LOKENSGARD E., Industrial Plastics Theory and Applications, Cengage Learning, Boston, 2015, p. 223.

20.ADHIKARI R., DAMM C., MICHLER G.H., MUNSTEDT H., BALTA-

CALLEJA F.J., Compos. Interface 15 (5), 2008, p. 453.

21.DANESHFAR Z., GOHARPEY F., J. Polym. Res. 23 (8), 2016, p. 1.

22. DUAN Y., THUNGA M., SCHLEGEL R., SCHNEIDER K., RETTLER E., WEIDISGH R., SISLER H.W., STAMM M., MAYS J .W., HASYICHRISTIDIS N., Macromolecules 42 (2), 2009, p. 4155.

23.VIDAL A., HAIDAR B., Soft Mater., 5, 2007, p. 155.

24. HARRATS C., THOMAS S., GROENINCKX G., Micro and Nanostructured Multiphase Polymer Blend System: Morphology and Interfaces, CRC Press, Taylor and Francis Group, 2005.

25.KRISHNAMOORTHI R., SILVA A., MITCHELL C.A., J. Chem. Phys. 115,2001, p. 7175.

26.SILVA A., MITCHELL C.A., TSE M.F., WANG H.C., KRISHNAMOORTHI

R., J. Chem. Phys. 115, 2001, p. 7166.

27.PAVLOV A., KHALATUR P., Soft Mater., 12, 2016, p. 5419.

28.THOMAS S., GROHENS Y., JYOTISHKUMAR P., Characterization of Polymer Blends: Miscibility, Morphology and Interfaces vol. 1, Elsevier, 2015.

29.GHIOCA, P., IANCU, L., VULUGA, Z., SPURCACIU, B., GRIGORESCU, R., IORGA, M., FLOREA, D., Mat. Plast., 53, 1, 2016, p. 34.

30.FLECK F., FROLOV V., KLUPPEL M., Polymer - Filler Interphase Dynamic and Reinforcement of Elastomers Nanocomposites, Taylor \& Francis Verlag, 2014.

31.FORNES T.D., PAUL D.R., Polymer, 44, 2003, p. 4993.

32.LEE K.Y., PAUL D.R., Polymer, 46, 2005, p. 9064.

33.LEE K.Y., KIM K.H., JEOUNG S.K., JU S.I., SHIM J.H., KIM N.H., Polymer, 48, 2007, p. 4174.

34.SEN S., THOMAS J.D., KUMAR S.K., KEBLINSKI P., Macromolecules, 40, 2007, p. 4059.

35.HBAIEB K., WANG Q.X., CHIA Y.H.J., COTTERELL B., Polymer, 48, 2007, p. 901.

36.MESSORI M., in Recent Advances in Elastomeric Nanocomposites, Advanced Structured Materials., edited by Mittal V. et.al., SpringerVerlag, 2011, p. 57.

37.FETTERS L.]., LOHE D.J., COLBY R.H. in Physical Properties of Polymers Handbook edited by MARK J.E., Springer, 2006, p. 445.

38.WATANABE H., Macromolecular Rapid Communications, 22(3), 2001, p. 127.

39.ELFADE A.A., KAHLAN R., HERMANN A., NOVIKOV V.N., ROSSLER E.A., Macromolecules, 43(7), 2010, p. 3340

Manuscript received: 27.02 .2017 